\title{
Monetary Theory of the Genesis of the State, Prospects for Electronic Money and Transnational Law
}

\author{
Daniyar Sarsembayev*
}

\section{N. Gumilev Eurasian National University, Nur-Sultan, Kazakhstan}

\begin{abstract}
This article is an attempt to explain a new way of the cause of the emergence of the state with simultaneous consideration of previously known theories in legal science. Several arguments are presented in favor of the new theory, which, in the author's opinion, are sufficiently valid. The author analyzes the dynamics of the development of the causes of the emergence of state and law and its influence on the transformation of the latest civilizations, which took place in history. Based on the historical chronology of the emergence and functioning of money, the author conventionally differs three stages in its development: 1) the period of the gold standard or a chronic shortage of monetary liquidity; 2) the period of paper money and inflationary pressure; 3) the digital money period. The author upholds a new position regarding the essence of international law, believing that international law is not a separate system of law, but only the result of the evolution of law from national to international, which became possible thanks to the development of the institution of money. The author shares his thoughts on the true reason for justifying the state's right to war in international law a while back, expressed in a persistent shortage of monetary liquidity, which took place from the moment the first civilizations appeared until the 20th century. This article establishes a projection for the further development of state and law, including international law, alongside the inevitable transition of the world community to the digital money supply. The article reveals not only the vision of the new monetary system, its absolute transparency, and clarity but also the various opportunities we face in such a transition. In this regard, the states and the world community will come to clear and effective outcomes in management, to the practical abolition of corruption and economic crime, to legal methods of conducting all competitions and public procurement, to fair and effective justice, and the establishment of highly moral relations in society.
\end{abstract}

Keywords: Law, monetary liquidity, transparency, international monetary and financial law, digitalization.

\section{INTRODUCTION}

There are many definitions of what the state is and no fewer theories about what caused it, starting from the patriarchal theory, which is briefly substantiated by the expression "the family is the cell of the state" to the Marxist-Leninist theory, which is based on the permanent class struggle. At the same time, when studying these theories, one gets the impression that these scientific views still reveal only certain parts of the large-scale process of state and law formation. This article substantiates the monetary theory of the emergence of the state.

The introduction of electronic money will beneficially contribute to the development of national economies of states and the world economy, and suppress corruption, economic and other crimes (Orlova, Afonin, Voronin, and Akopyan, 2015; Lebedeva and Orlova, 2019; Vasilleva and Nilova, 2011). In this regard, the author of the article comprehensively substantiates the concept of the need to introduce electronic money into the financial system of each state.

The essence of the state and, accordingly, its definition lies in the essence of the person himself, or

*Address correspondence to this author at the L. N. Gumilev Eurasian National University, 2 Satpayev St., Nur-Sultan, 010000, Kazakhstan; Tel: +7 -701-91590-60; Fax: +7-7172-70-94-57; E-mail: daniyarsarsembayev@mail.ru rather his nature, but not only from the point of view of the psychological need to rule and obey, to live within the organized society, and the presence of a sense of collective mutual action, in the opinion, on the one hand, of the philosopher Aristotle, the English legal theorist R. Filmer, the Russian scientist N.K. Mikhailovsky within the framework of patriarchal theory, and on the other hand, of L. Petrazhitsky within the framework of the psychological theory of the emergence of the state. To make the picture complete, the following classification of theories of the emergence of the state is presented.

Representatives of theological theory (Aquinas, 1990) in the Middle Ages believed that the state was created by God's will. The patriarchal theory (Dunning, 1900; Mikhailovsky, 1909) proceeded from the "paternalistic and authoritarian" analogy, according to which the sovereign's power is as unshakable as the father's power in the family. The contractual theory (Grotius, 1956; Radishchev, 1958) proceeded from the premise that the state originates as a result of an agreement between people, their associations, based on which they transfer part of their powers to the supreme ruler - the state. According to the theory of violence (Kautsky, 1905), a tribe that conquered another tribe imposed its power, which was called the state. The creators of the organic theory (Spencer, 1908; Vasilyeva, 1977) believed that the state can be 
considered a separate organism, similar to the human one, between the parts of which there are interrelated processes. The essence of the materialist theory (Engels, 2014) is that the state appears as a means of carrying out the will of the wealthy people, aimed at protecting their economic interests. The reason for the emergence of the state according to psychological theory (Petrazhitsky, 2020) lies in the peculiarities of human psychology, in the need of some people for power over other people. The racial theory (Gofman, 1977; Nietzsche, 2005) considered the human races to be unequal in terms of the physical and psychological characteristics of the individual: the need to lead the lower races became the reason for the emergence of the state. Disagreeing with the above theories, the author of the article substantiates a completely new, monetary theory of the origin of the state.

\section{MATERIALS AND METHODS}

Suffice it to say that only a reasonable person (homo sapiens) has been outside the family and the state for a long time since his existence. And if we take into account human psychology on its own, then it does not explain why it was the state that became that stable organization of society, and not, for example, a commune. Also, a society with its psychology could generally stagnate at the level of a clan or tribal organization. As was the case with the aboriginal Society of North America and Australia, before the arrival of Europeans. Thus, the indigenous population of Australia, with its existence for 50 thousand years, is a clear example of the fact that a person could live without a state to this day and proof that it was precisely the absence of an appropriate stable system that prevented them from advancing to a more organized society.

The materials for this article were monographs, articles published in scientific journals, statistics data, arguments built in the process of scientific disputes.

The research methods used in this article are as follows. Among the methods is the historical method, when the monetary theory of the origin of the state is based on historical facts, and the connection with the modern theory of electronic money is based on the combination of history and modern age (Malhasyan, 2013). Methods of analysis and synthesis are of help to work out the main provisions of the article. Thanks to the method of comparative analysis, it was possible to trace the features of money circulation in different periods. The topic of this article is revealed through the analysis of the norms of domestic, foreign financial, monetary, administrative, and international monetary and financial law. Problematic issues of the topic are settled based on national legal and international legal scientific literature. All this taken together makes it possible to improve the monetary and financial legislation of each country and the monetary and financial transnational law.

\section{RESULTS AND DISCUSSION}

It is peculiar that a person is born with unlimited needs that lead to the consumption of resources given to him by the earth and its interior: food, clothing, home, information, communication, security, etc. In general, the list of resources is limited only by their variety, but I would like to dwell on the above because it provides a sufficient basis for presenting the main idea of what a state is.

Even though when appealing to such a concept as the state, lawyers try to refer to the legal side of the issue; the state still seems to be a stable form of organization of society by establishing, and also transforming, distributing, and consuming limited resources in this society. According to a more concise definition, then, having omitted all the stages associated with production and trade, we can broadly say that the state is the organization of society for the consumption of limited resources. And the more limited the resource, on the one hand, and the higher the need of a person and society for it, on the other, the higher its value. The transformed resource is initially more limited since it requires the involvement of production factors (Orlova, Sakhabieva, Vasyaycheva, and Pronina, 2016).

The author of the article argues that the state as an administrative apparatus appeared as a result of the emergence of money, money supply, gold, and other precious metals as a medium of payment, as a result of the need to issue money, the need to ensure control over the proper amount of money to avoid inflation and hyperinflation, which is sought through the norms of financial, budgetary, and currency law.

The introduction of electronic money should be systematic, the concept for its introduction should be scientifically substantiated, and the argumentation should be accurate and verified. The introduced electronic money system should be free from the drawbacks of currently functioning cash. Cash paper and metal money should be cancelled by stages through the rules of administrative law. 
It would be advisable to think over, develop, and adopt new national laws, regional and universal conventions on the introduction of electronic money into the monetary and financial systems of states and the world.

While studying the above definition of the state in detail an understanding emerges as to why this organization of society has an appropriate list of features, such as public authority, territory, population, taxes, army, etc. When considering the root of the problem, then behind every action of the state, be it a war or cooperation, or the adoption of internal acts, there is a mostly mere economy, and the economy, if we omit all its details (production, trade, shares), is, in the end, consumption of limited resources. Whether we like it or not, it is impossible to go far from Mother Nature, who conceived us. By the way, she conceived the limited resources, which predetermined the future development of society.

But from the above definition, the reason for the emergence of such a phenomenon as the state does not follow. The organization of consumption of limited resources by society also took place before the first signs of statehood appeared and was fairly carried out by a clan or tribe, which resorted to the establishment of traditions and customs to ensure order. Before starting to consider this issue, I would also like to note an unequivocal fact in the irrigation theory put forward by Karl August Wittfogel stating that a sustainable organization of society could arise only next to the water in sufficient quantities to meet one of the main human needs for quenching thirst and hunger. But the claim that it was the organization of water distribution through irrigation that became the reason for the emergence of the state seems to us rather groundless and controversial. His theory substantiates more the reason for the choice of the place where the states arose than the reasons for their emergence as such. Let me recall that, in principle, to satisfy the vital human needs for water, food, shelter, and communication, the state is not necessary. The history of mankind has millions of years, and, as noted above, Homo sapiens appeared about 40 thousand years ago and coped with their needs without this institution for almost 35 thousand years. It should be noted that the premises for the emergence of the state are the unification of people into a kind of society, but not only the process of grouping through unification and natural growth is characteristic of a man, but also a craving for disintegration, like children leaving the care of their parents, which again undermines the theory of Aristotle and Petrazhitsky about the emergence of the state. So, in particular, among certain peoples, despite the presence of statehood, to the present day, signs of tribal affiliation are traced. While studying their history, one can see that these tribes themselves were subject to dividing into subtribes and even into new tribes, i.e., there is an equally stable and constant process of separation of people. The same thing happens with the peoples (Anglo-Saxons, Slavs, Turks), which, as history shows us, fell apart into minor peoples. And if the statement about the propensity of society to disintegration were incorrect, then, probably, there would not exist such a number of states, and society would initially have been established under the flag of a unified world government. What made people, despite such a tendency, still overcome the primitive clan system and form into a more complex organization like a state, which, among other things, is a fairly stable phenomenon? After all, civilizations appeared and disappeared, but new ones came afterward, and today the UN includes altogether 193 member states and two observer states. From this, it follows that a person stubbornly insisted on the existence of this phenomenon and his existence within it.

In the 12th-10th millennium $B C$, the transition of a person from foraging to producing economy became the beginning of the path to a complex organization of society, but it does not seem to have a direct causal relationship with the emergence of the state, something should have appeared between them, something that made society go not to the formation of a commune, distributing manufactured products according to the principle "From each according to his ability, to each according to his needs," namely, to the creation of a state.

Many schools of economics, from mercantilists to monetarists, answer this question. Obviously, these schools did not set themselves the goal of revealing the concept of the state and determining the causes for its emergence, and this is understandable, since they are economists, and the origins, essence of the state and its activities, according to the established opinion, have always been political and legal categories, which, according to the author of this article, is not entirely justified. So, in particular, Nicolaus Copernicus's treatise on minting coins and Murray N. Rothbard's book "What Has Government Done to Our Money?" deal with a universal medium of exchange, a commodity that evolves to the state known today as digital money and which seems to be the very reason for the emergence of the state and law. 
With the emergence of a universal product with properties such as a medium of exchange and measure, the process of market relations was launched. The exchange between people has become so convenient and simple that people need deeper integration since all manufacturers of a particular product simultaneously saw in each other a source of new resources for consumption that they do not possess and potential consumers of their products which they manufacture. Markets began to establish where trade was in full swing, using which everyone could constantly improve their welfare, i.e. expand the range of consumption of limited resources (Progunova, Trokhova, and Milonova, 2019). The assumption has sufficient logical justification that the squares, which now symbolize the place of political achievements, in the first cities were originally markets for trade.

The first forms of the medium of exchange, be it cattle, arrowheads, shells, coins, like glue, firmly fastened people's interest in each other while creating the opportunity for a part of society to gradually move away from agricultural activities and master crafts as an independent economy and occupation, including the profession of the state management. In other words, money became the reason for the emergence of such a concept as the division of labor. Also, the first wave of technology was heralded. And it is important to note the psychological moment that the part of society that ceased to produce essential products turned out to be more dependent on commodity-money relations than ever since they had a very strong need to exchange their labor outcome for food at all costs, which forced them to advocate for the preservation and development of more complex integration.

The question about when gold and silver began to be used as a medium of exchange, and whether they are namely the object having the appropriate quality that united people in such an organized society as a state, remains open. But archaeological finds are thought-provoking. According to the latest archaeological data, the first ancient gold items found in Bulgaria in the Varna necropolis date back to the end of the 5th millennium BC (4600-4200 BC).

It is also believed that silver has been known since ancient times around the 4th millennium BC. So that, the emergence of the Sumerian (first) civilization, according to historians, falls in the middle of the 4th millennium BC. There are interesting coincidences. It is worth noting an argument that the introduction of gold and silver into circulation was not the work of the state apparatus, one can refer to the Thracian tribes who were able to achieve only the formation of particular features of statehood, but were already mastering gold mines.

Together with such a property of a universal commodity as a medium of exchange, its property such as a means of preserving the results of labor, i.e. accumulation (it is fair to say that accumulation is characteristic of any commodity, taking into account, of course, the specifics of its storage) became the reason for the emergence of such social institutions as private property, classes and, accordingly, public authority, laws, and taxes. Further, with the development of commodity exchange, the universal product acquired a monetary form and thereby strengthened state institutions and the state as a whole.

It is very important to note here the connection between the universal commodity and power. Many authors of books on economics, numismatics, and other social sciences point out that money is power. Here a large field for speculation arises, which inclines to think that (public) power is not a feature of the state, but primarily a property of money. And most likely, money, which has strengthened as a medium of exchange and accumulation, only endows the people who have money with such power, and, accordingly, the state authority. And therefore, if you overthrow a particular person endowed with public power, or destroy a particular civilization, as, for example, the Roman Empire, public authority as a phenomenon is not lost as long as money exists and the former king is replaced by a new one, and old civilizations are substituted by the new ones. Accordingly, public power appeared due to a sufficiently accumulated medium of exchange in society (whether it aswas coins or even ingots or another commodity) and the need, on the one hand, in preserving the status of a valuable thing in the medium of exchange, and on the other, in its protection. The reason for the empowerment of the authority was most likely the institution of the elites, which had a high level of trust in society and, due to the highest savings, needed protection more than anyone else. Since the state apparatus still exists and retains this power, then we must give credit to the monopoly for the minting and the monetary fund which is the largest and most efficient in terms of distribution. It should be noted that power implies subordination, and it is most likely formed due to the peculiarities of human consumption of resources. Human needs are multifaceted. As a rule, when choosing food, clothing, or other goods, we try to diversify them and do not 
forget that each person has individual preferences. And as mentioned above, only a universal product can provide an expansion of the range of consumption. A person will give preference to subordination, not to someone who has a lot of food or clothing, or houses, or cars, but to someone who has a universal medium of exchange due to which everyone can buy a house, a car, and a lunch. Summing up this paragraph, we can conclude that public power as a feature of the state is a pure product of money.

The people can delegate to individuals, in particular, and state bodies as a whole, the right to such power and deprived of this right even using revolution. It is the people who take the first place in ensuring the development of the economy and, accordingly, monetary flow; it is they who have the largest "public monetary fund" and form the state budget by paying taxes.

When society gradually began to give preference to a commodity such as a precious metal as a medium of exchange, the state as an organization strengthened its position, taking over functions of the issuer of coins somewhere during the interval of the 1st millennium BC (it is this period that dates back to the first coin in history, struck in Lydia), which initially did not have a nominal designation in the form of numbers, and their buying capacity was measured in weight.

This explains the emergence of the contractual theory of the origin of the state. In his works, Epicurus emphasized that the state rests on the mutual agreement of people on justice. But if one can accept it, then only partially. No matter how cynical it may sound, if there was such an agreement, then most likely its subject was not justice, but the organization of the gold and silver circulation in commodity exchange, even if it was fair. Under this agreement, the society came to terms that gold and silver, even though they do not represent a primary consumer value, must possess a comprehensive feature, and under this agreement it transferred, first of all, the right to strike coins to the state. It has become and to this day is the basis of this organization. It is important to note that coins, or rather the precious metals contained in them, besides all other properties, had such features as trust. This feature, without exaggeration, underlies the emergence of a universal product. It took shape in the process of a long development of market relations and consisted in the fact that everyone who sold his limited resource (product, work, or service) for a coin (or another medium of exchange) was confident that he could get another limited resource of equal worth for the same coin next day. But even then there were frauds, which undermined this trust, passing off other metals for gold and silver. There were also those (thieves, robbers, muggers, swindlers) who tried to take away precious metals accumulated for years by force or deception. And when the state was given the right to strike coins, in return it promised the people to maintain the people's confidence in gold and silver and coins made of them, preventing counterfeiting on its part, punishing those who live on it, and protecting those who have them. All of the above, i.e. organization of circulation, maintenance of trust, protection, and punishment to protect became the reason that the state resorted to such a mechanism as law. In other words, a law was one of the tools for organizing the distribution of society's resources through the commodity-money exchange. It was the transition from barter to the sale of goods that caused the transition of society from the norms of morality and customs to laws.

However, history shows that from time to time the government machine allowed mischief in coinage, thereby jeopardizing public confidence. So, the king of France Philip IV was nicknamed the Counterfeiter King. So, the statements about justice as the basis of statehood are far from reality.

Nevertheless, something suggests that when being on the horns of a dilemma, Philip alone is better than impunity of a horde of counterfeiters. So, the event of 1125, known as the Bloody Christmas, is associated with Henry I, when he invited all the minters and, by his order, all who were caught red-handed (and that was everyone) in counterfeiting coins got their right hands cut off. It should be admitted that the government apparatus is for the most part inclined to maintain order since it is it that ensures the preservation of the right to power, which cannot be said about private individuals pursuing personal selfish interests.

The first government-minted coin commemorated the following:

- $\quad$ the beginning of the evolution of a universal commodity into money; coins gradually began to oust other forms of media of exchange from circulation;

- the launch of a slow, but steady process of absolute monopolization of the emission of the media of exchange of goods by the state, which most likely led to the fact that the reason for the 
emergence of the state was gradually transformed in the contemporary's consciousness into its feature, one of the pillars of its sovereignty. In Europe private coinage was practiced for a long time. Moreover, common urban dwellers had the opportunity to bring their ingots to the mint and make coins from them. And only in the 16th-17th centuries, the entrance to the mints was closed to individuals.

And here, before continuing to dwell on the process of evolution of money and, accordingly, the state and the institution of power, I would like to draw more detailed attention to such an important point as the transition of society from ingots to coins. The most important question in this topic, which arose not only for economists but also for lawyers and political scientists, is the need to find out the reasons for such a transition.

I cannot believe that the primary reason for minted coins was their ease of use as a payment. I am more inclined to the general laws of the limited resources and their consumption, in other words, the laws of nature.

So, gold, and then silver, against the background of basic human resources such as water, food, clothing, and in a certain period, iron, were non-renewable and the most limited resources from the very beginning (if we omit certain insignificant stages from the point of view of history). This became, if not the only, then one of the main reasons for them to acquire property such as a medium of exchange. Gold and silver were most likely initially considered to be a luxury desired by everyone, and as their production grew, they became a measure of the value of any other good, work, or service.

As the population grew, so did the volume of consumption of limited resources (and, accordingly, production, always keeping ahead of the volume of demand), which, as noted above, were distributed in society employing commodity exchange using ingots of precious metals as a medium of exchange. At the same time, the rate of production of gold and silver did not significantly keep up with the production of other types of resources, but meanwhile, due to their recognized property as a means of exchange, they remained the resources mostly used in the process of commodity exchange.

It should be noted that with an increase in the volume of resource consumption, the highest value is acquired by the resource that is both the most limited and the most consumed (or used) in the process of their distribution, and gold and silver are no exception to this rule. Which of the above two categories most affects the value of the resource is a separate question. Also, the limitedness of gold and silver was also influenced by people's preference for their accumulation. Since all this led to the fact that nothing but precious metals grew in value, everyone tried to invest their labor in them, which made them even more limited. In other words, the amount of gold in circulation has always been less than the volume produced in gold mines.

Accordingly, the value of gold and silver concerning other goods grew and ingots became more and more expensive. If earlier one could buy one sheep for a certain amount of gold, then after some time there is a constant increasing gap between the volumes of mined precious metals, or rather, those being in circulation and volumes of other resources. The difference in their value was so big that a whole flock was already offered for gold of the same weight. In this regard, the need arose to reduce the size of ingots to the size of a coin. In other words, from the very beginning, as a person faced gold and silver and began to use them as a medium of exchange, society followed the path of expensive money (or lack of liquidity), in which precious metals were not only constantly lacking, but also with further population growth and the volume of consumption of limited resources, they were on the decrease.

In addition to the search for new deposits of precious metals, states sometimes solved this problem with wars and robberies of gold and silver reserves from other peoples. It was not uncommon and, of course, it could not but lead to the emergence of such a theory of the emergence of the state as the theory of violence, which also only partially reveals the process of the emergence of the state and which was promoted by the German philosopher economist Eugene Dühring and the Polish sociologist and political scientist Ludwig Gumplowicz (Gumplowicz, 1910).

The true cause of all wars (internal and external) always lay much deeper than the trivial enrichment with trophies and the enslavement of other peoples. The goal of the conquerors, whether they understood it or not, was not the resources of the captured state, since even the most powerful czars-military leaders (Genghis Khan, Alexander the Great, Napoleon Bonaparte) did not receive all the trophies, but could only count on 
their share, even a significant one. Wars served only as a means of maintaining the national system of distribution of resources in the society of the aggressor, on which the continued existence of such conquerors' power depended. Those governors who did not cope with this task usually became victims of palace coups, and subsequently revolutions. And if the captured villages and castles were not of primary interest, especially if it was impossible to include them in the commodity-money circulation in the invader's country, then trophy gold and silver were a priority, since they were the main component in this distribution system, also, they were in persistent deficiency. In simple terms, military expansion, as a rule, resulted from the problems within the state, and not between countries, and, accordingly, was aimed at solving them. Though today the state cannot be imagined without elements of coercion, the security apparatus of the state is not a manifestation of power, but the result of the need to protect it; and attempts to replace the true source of power with force (military, law enforcement) or propaganda have always failed. This is confirmed by historical examples of empires, including, and maybe even, first of all, the USSR, when they tried to keep and control society by propaganda, force, or intimidation. The country of the Soviets had all the resources (knowledge, oil, gas, metals, land, water, etc.) necessary to create an unlimited range of goods, works, and services, but there was no effective money distribution system focused on the financial motivation of a particular individual and society as a whole.

One way or another, but having chosen precious metals as a medium of exchange, society entered the first stage of its development within the framework of such a social phenomenon as the state, which can be conditionally designated as the monetarist period.

It should be emphasized that this period was characterized by a persistent shortage of liquidity, which, among other things mentioned above, was caused by the fact that the purchasing power of the medium of exchange was measured in weight. It should be noted that this persistent deficit has been holding back the integration of society and the development of law at a new level for many years. The widespread lack of a medium of exchange forced peoples and states to fight among themselves more than to establish full-fledged peaceful cooperation.

Initially, in the monetarist period, the main centers of concentration of the medium of exchange and, accordingly, power were the state machine, as well as religious institutions. The formation of a state philosophy on the principles of "I am the state", "I am the law," "power is subject to inheritance" is explained by the fact that it was the state apparatus at that time, represented by the monarch and his court, which had the largest capitalization of funds for many years and there were no other equal social institutions and groups in capitalizing that could resist it. This is explained by the fact that, also, the state apparatus had the right to minting and levying taxes, its significance was predetermined by the form of resource allocation that had developed in society, which is pyramidal, i.e. those at the top of the distribution pyramid tend to gain the bulk of control over resources. And accordingly, the distribution of money supply during its emission also inevitably takes the form of a pyramid. But money and resources are characterized not only by capitalization, but also by flow; they flow from one owner to another; new centers and pyramids are formed, which took place in Europe in the 17th century, when the bourgeoisie formed a new pyramid of distribution of funds and demanded that the monarch should legitimize this system and, accordingly, the recognition of their right to power.

The above factor is considered in the MarxistLeninist theory of the emergence of the state as a cause, but as already mentioned, this is most likely only part of the complex process of the establishment of such a form of organization of society as the state. Besides, history demonstrates that classes tend to coexist rather than struggle. The conflict between them arises only from time to time, when the financial paradigm changes in society, when the efficiency of the old system of distribution of resources in society, primary money, decreases to the level when "elites can't and people don't want to."

Persistent deficit forced society to turn towards the nominalist concept, which formed the basis for a new second period in the development of society and the state. England was the first in Europe to resort to legal mechanisms through which the principle of nominalism was enshrined. When, in 1604, within the framework of the Gilbert v. Brett case, the question was raised of what the subject of a pecuniary obligation was. The English court, having upheld the monarch's right to "spoil" the money, abandoned the idea of the coin's purchasing power in favor of the amount of the monetary unit indicated on the coin, and thus officially set apart the estimate of the value of the coin and the actual weight of the precious metal contained in it, and 
associated it with the denomination. This principle is enshrined in the laws of many countries, in particular, in the civil codes of France, Belgium, the Netherlands, Spain, Italy. This principle was also reflected in US law. Lawyers in the knowledge of alchemy have bypassed even the most advanced newly appeared sages.

The entrenchment of this principle was the first step towards the introduction of paper money into circulation, which ultimately solved the main problem that kept the economic development of the first civilizations and medieval states in chancery - liquidity shortage (Mokeeva, 2019). The new medium of exchange laid the foundation for unprecedented technological advancement in the 20th century. As a result of it, a middle class appeared. The specialization of labor acquired a new quality; deep integration of society became possible not only at the regional but also at the universal level. Many new associations appeared in the form of international organizations, and international law expanded (International, 2009). The availability of paper money has created favorable conditions for the development of stock markets and commodity exchanges. New centers of concentration of money supply began to form - private financial organizations, transnational corporations. The state apparatus of the countries of the world began to abandon the monarchical form of government in most cases under pressure from new influential social groups of financiers and industrialists.

However, some unresolved issues in the monetarist period related to the institution of money have remained open to this day. In particular, the issue of the wealth gap between the poor and the rich remained pending. And it is related to the fact that the state did not take the measures necessary to ensure the diversification of the money supply among the population on a systematic basis. Such diversification has remained ad hoc in history. An example of such diversification may be the decision taken by Henry Ford in 1914 to raise workers' wages. Moreover, such diversification was most likely associated primarily with the growth of the money supply in the economy and the growing tension between entrepreneurs and the working class, rather than a one-sided strong-willed decision. But even such small steps were able to form a middle class in society.

Also, new problems emerged, extremely opposite to the problem of the persistent deficit. This is, in particular, inflation, which in some countries grew into destructive hyperinflation.
The overcapitalization of funds privately owned can also be attributed to the new problems generated by paper money. In this case, the problem is not in the fact that money is capitalized privately, but in that, they cease to circulate in the real sector of the economy and therefore do not benefit the progress of mankind. Money must be capitalized only to go back into circulation. States collect taxes and develop a budget, the bulk of which goes back to the economy in the form of wages, road construction, schools, and other social projects. This mechanism should also be launched about high private finance concentrated in one pair of hands or a small social group. Money should not be held in banks for a long time, especially if the accounts are in offshore zones. At the moment, a situation is emerging when private capital does not want to take on more social responsibility than paying taxes, thereby forcing the state to issue more money, undermining the value of money. Accordingly, this ultimately affects everyone, including private capital. And until private capital and the state start negotiating, society will experience financial difficulties like inflation and other economic troubles. It appears reasonable to redefine the role and significance of private capital and understand whether the economy needs billionaires. It may be necessary to reconsider the right of private individuals to inherit billions of dollars, as the state did concerning the unlimited right of the monarch to power, which was also expressed in the right to inherit it.

Paper money has intensified the trend of tax planning and hiding tax revenues, which negatively affects the flow of capital and investment.

Tax evasion and black markets for drugs, weapons, and slavery are particularly problematic. The issue does not only relate to the fact that these markets are criminal and dangerous for society, but also that illicit funds formed in these markets are intrinsically hidden from taxation and cannot return to legal circulation for a long time, also forcing states to resort to a new issue of currency.

In 2009, a new format for monetary circulation appeared in the world financial system. The term "cryptocurrency" came into use after the emergence of the bitcoin payment system. The states viewed differently this phenomenon. Someone began to create the necessary legal conditions for the development of this currency. Others, on the contrary, made legal barriers against the penetration of this currency into the civil circulation of commodities, works, and services. 
Cryptocurrency is a kind of electronic money per se. The latter has long been known to the financial world. However, the peculiarity and revolutionary nature of this currency lie in the fact that it has no material or physical expression in the form of precious metal or banknote. This factor promises breakthrough opportunities for all of humanity. Let us take a closer look at this breakthrough.

First, the system of distribution of the money supply will reach a new, qualitatively transparent level. The state will see industries with an excessive concentration of money capital and sectors experiencing their persistent deficit in full view. Accordingly, the states will be able to timely take measures to stimulate the money supply flow from places with its surplus to the spheres that need it. The problem of involving citizens' savings in the country's financial turnover will be solved, and mattresses and glass jars as particular keepers of money will fade into history. It should be noted that these practices will allow the state to less frequently turn to the additional issue of electronic money, which will effectively curb inflationary processes. At the same time, it will become possible and necessary to consider the issue of creating an electronic system focused on the money supply deflation and its impact on the circulation of electronic money. It seems that it is the deflationary approach that will respond more timely and objectively to the requirements of ensuring commodity circulation in the economy. It should be noted that Bitcoin is based on this particular system.

The state will be able to bring control over pricing to a new level, prevent abuse of monopoly, and the formation of fixed super-profits.

Taxation will become transparent as never before, gray markets for the circulation of goods, works, and services will completely disappear. Perhaps the taxes, their types, and taxation mechanisms will change dramatically. It can be assumed that taxes are converted into a transaction fee.

Subjects of financial activity will have a level playing field. Perhaps the state will strengthen its positions in the distribution of the money supply, taking up separate, or, possibly, all the functions of second-tier banks. Credit money will accordingly become more accessible and cheaper.

Ultimately, the redistribution of national wealth among its members will become more smoothed and diversified in favor of the lower strata of the society, and the number of representatives of the middle class will increase. It may happen that the process of growth of the average wage index will begin, not based on inflationary pressure or the use of administrative leverage.

A more perfect system of circulation of the money supply may act as a trigger that can give impetus to a new technological process, and possibly all subsequent ones.

Secondly, digital currencies that do not have a physical form, or rather their system, possessing significant transparency in circulation, when each transfer of such money from one e-wallet to another wallet will be noticeable, will allow you to trace when, in what volume and between whom any transaction took place (Uvarova, 2013; Yakhneeva, Agafonova, Fedorenko, Shvetsova, and Filatova, 2020). This money cannot be stolen, hidden, or used for other criminal or immoral purposes without an absolute guaranteed risk of disclosing such actions and bringing to justice the persons who committed them (Asnawi and Setyaningsih, 2020; Muktiyanto, Dwiyani, Hartati, Perdana, and Possumah, 2019).

It is a fair assumption to say that committing the most socially dangerous acts enshrined in criminal and administrative legislation will be minimized, and in most cases, the payment of administrative and criminal fines will become inevitable and timely.

With the abandonment of paper money in favor of their electronic circulation, the distribution of budgetary funds will become transparent, which, on the one hand, will reduce corruption-related risks, and on the other, will increase the quality of goods, the provision of works and services in the public sector. Corruption is likely to be reduced to everyday manifestations.

All money that will be stolen by fraud, theft, robbery, appropriation, and other methods will almost automatically be returned to the injured party. Electronic money transactions will become indisputable evidence of the participation of certain persons in criminal schemes.

States will receive powerful leverage in combating such offences of international concern as trafficking in arms, drugs, other dangerous substances, slavery and prostitution, financing of terrorism (Shaw, 2017), since any unreasonable concentration of digital money on certain accounts of individuals or legal entities will 
proactively attract the attention of both the public and law enforcement agencies, thereby preventing the criminal community from uniting into sustainable organizations and groups. Mafias and big cartels will fade into history. Any methods of money laundering will become ineffective and inexpedient. Counterfeiting (counterfeiting of banknotes) and, accordingly, some provisions of national legislation and international agreements related to this phenomenon will become history.

The money supply and other resources that have been involved in the processes of criminal business for many years will inevitably go into legal areas of activity, causing a positive impact on the economy. How will it be carried out? Two ways are possible here:

1) the prohibition of exchanging paper money for digital without confirmation of the legitimacy of income. In this case, criminal organizations will be irrelevant with their old money (banknotes), and the states will be able to restart the released volumes of digital currency supply through the issuance of new loans or the establishment of state programs;

2) carrying out a series of legalizations of the money supply during their transfer from paper to electronic form. In this case, criminal communities will be allowed to come out of the shadows and turn their focus toward legal activities.

Which of the above paths is correct? Here, it seems to me, each state should decide it taking into account the peculiarities of its national economy and social order.

It should be noted that the civil law sphere will also undergo positive changes. Obligations under civil contracts will acquire whole new guarantees for their performance. Relevant problems related to alimony obligations will be solved in particular countries.

Third, a transparent monetary system will inevitably make clear not only the activities of state authorities but also political groups (parties, clans, etc.). The struggle for power and its retention in countries with market economies will become more transparent and, accordingly, competitive. Attempts to finance the forced change of government will become more predictable, and law enforcement and other bodies will have the opportunity to identify and suppress the entire scheme and circle of participants in such funding. Credibility channels will gradually give way to other progressive methods of struggle for power or its part. Perhaps the branches of government will become more independent from each other, and local authorities will become more self-reliant, i.e. the processes of decentralization of power will intensify. Recognition de jure of such a phenomenon as lobbying will become inevitable.

Realizing the importance of the monetary system for the state as a phenomenon, it becomes clear that the efforts of states aimed at digitalizing the state sphere (the activities of state bodies and the services they provide for society) and the economy as a whole are made from the end, which, of course, does not allow disclosing the real extent of strategic objectives, but forces you to work pointwise at the operational level, and in some cases by touch. And only the complete digitalization of the money supply will make it possible to go along with the main trends for further technological breakthroughs of mankind, the role of the state, and economic development.

How do I see an effective electronic money system? National digital money should be formed on a single platform administered by the central banks of states. In this case, the platform must be unified, i.e. there should be one electronic ledger that would record all possible transactions, as in the cryptocurrency example. Unlike crypt, all accounts must be identified, i.e. accounts should be assigned to particular individuals and legal entities. Each digital unit, like paper banknotes, must have its identification number, which will make transactions more transparent.

The process of digitalization of the money supply of states will be uneven. Some countries will rush forward, some will be cautious in reforms and lag. In this regard, those countries that will abandon the paper form of their money will have to absolutely limit the circulation of foreign currency in physical circulation on their territories and also transfer them to digital format. Central banks will have to take on the function of keeping these currencies and timely operate with them, whenever required when executing foreign economic transactions by the entities of civil circulation.

This system should become an object of national security and is carefully monitored by not only intelligence services but also all law enforcement and fiscal bodies. 
Operations of certain categories of persons, such as government officials, government bodies, pseudogovernment organizations, should be made available to the public and government bodies. It seems necessary to introduce the concept of preventive monitoring of monetary transactions of persons held accountable for crimes against property and participating in organized criminal groups into the punishment system in the criminal legislation.

It is necessary to ensure the uninterrupted operation of the system by duplicating the operation of several servers storing the same information, which in turn will also create a mechanism for protecting against committing fraud by hackers.

The states will face the task (the expediency and profitability of which will already be indisputable) of organizing proper cellular and Internet network even in the most remote area on their territory.

A highlight is a question about the future of the international monetary and financial system. What kind of system will it be? What kind of currency will it be based on? Will states we can support a system based on one currency, or will we face the process of its regionalization? However, against the background of the above questions, one thing seems clear to me, that in whatever direction the world community would go as regards this matter, the system should be completely digital without a paper analogue. In addition to the advantages mentioned in this article, the world community will be able to once and for all resolve the issue of the harmful influence of offshore zones and the fight against gray foreign exchange markets. By reducing the risks of financial fraud and strengthening trust between the subjects of foreign economic activity, international trade will become more intensive and secure, and the amounts of both counterfeit products and trafficking, in general, will decrease. We will be able to improve the efficiency of the work of international financial institutions in the distribution of world capital among states, distinguish between countries that need investment and countries with sufficient domestic funds, and also see in detail the causes of problem loans and, accordingly, increase the level of international investment returns. It seems that digital money will strengthen the process of international integration in all directions, and we will be able to observe drastically new transformations in international law, as well as in law in general.

Of course, so that the individual items (gold or precious metals) will not replace paper money, the world community must introduce additional restrictions on the free circulation of these metals.

\section{CONCLUSION}

To sum up, it seems to me that, despite the current ambiguous attitude towards digital currency, states will somehow have to recognize it and take charge of the establishment of the new payment system. The only question is whether this will come evolutionarily, or there will be a revolutionary struggle for an idea in society? Unfortunately, history makes it possible to state that the concept of "social evolution" is alien to human consciousness. New formations have always come with the "bayonets" of the reformers. Then another question arises, who are these reformers? Most likely these are representatives of the new "digital economy". However, as the row of recent events shows, they are not mature enough to take responsibility for the future of humanity. The people who created Bitcoin made it clear by their anonymity that they are not yet ready to advocate their idea. This is most likely because they are still getting along with representatives of the old economy. But it is only a matter of time. A new economy in the form of vending machines, Internet platforms, and remote-control systems is now replacing the traditional economy, and along with it, its representatives.

Despite the above questions, one thing seems clear - even though the new system of monetary circulation will not become a panacea for all problems, it will create more opportunities for us than risks. I am sure that a complete rejection of cash in favor of digital currency will have a positive effect on the circulation process in the economies of states and the world. Many negative phenomena, including criminal ones, will remain in history. Intellectual competition within society will intensify since illegal ways to make money will become largely inaccessible; education issues will reach a new qualitative level. The efficiency of taxation and social responsibility of private centers for the concentration of money supply will increase. In the era of honest money, the state and law, as phenomena, will acquire a new form and significance. The big state that nowadays introduces a new electronic money system will become the leader of the entire financial world.

\section{REFERENCES}

Aquinas, Th. (1990). On the rule of sovereigns. In: Political structures in the feudalism epoch in Western Europe in the 6th-17th centuries. Leningrad: Nauka, 233-243.

Asnawi, N., \& Setyaningsih, N. D. (2020). The role of DART key building blocks as customer co-creation determinants in 
Islamic banking services. Journal of Southwest Jiaotong University, 55(6).

https://doi.org/10.35741/issn.0258-2724.55.6.38

Dunning, W.A. (1900). The Politics of Aristotle. Political Science Quarterly, 15(2), 273-307. https://doi.org/10.2307/2140302

Engels, F. (2014). The origin of the family, Private property and the state. St. Petersburg: Lenizdat Publishing House.

Gofman, A.B. (1977). Elitism and Racism (criticism of the philosophical and historical views of A. de Gobineau). Races and Peoples, 7, 128-142

Grotius, H. (2012). On the law of war and peace. Cambridge: Cambridge University Press.

Gumplovich, L. (1910). General doctrine of the state. St. Petersburg: Printing House T-va "Public benefit".

International monetary and financial law (2009). In: International Law. Almaty (Republic of Kazakhstan): Zhetyzhargy, 200-202.

Kautsky, K. (1905). Development of the forms of the state. Rostovon-Don: Donskaya Rech Publishing House.

Lebedeva, L. G., \& Orlova, L. V. (2019). The city as a social space of interaction between generations. IOP Conference Series: Materials Science and Engineering, 603(4), 042062. https://doi.org/10.1088/1757-899X/603/4/042062

Malhasyan, A. (2013). Factors of formation of effective monetary policy in Russia. Journal of Contemporary Economics Issues, 2. https://doi.org/10.24194/21311

Mikhailovsky, N.K. (1909-1914). Collected works: in 10 volumes. St. Petersburg: M. M. Stasiulevich Publishing House.

Mokeeva, N.N. (2019). Money and the monetary system. In: Monetary theories / N.N. Mokeeva, A.E. Zaborovskaya, V.E. Fries. Ed. by N. N. Mokeeva. Yekaterinburg: Publishing House of the Ural Federal University.

Muktiyanto, A., Dwiyani, R., Hartati, N., Perdana, H. D., Possumah, B. T. (2019). Control combating corruption: A governance model from Indonesians' perspective. Journal of Southwest Jiaotong University, 54(5). https://doi.org/10.35741/issn.0258-2724.54.5.21

Nietzsche, F. (1968). The will to power. Ed. by W.Kaufmann. New York: Vintage.

Orlova, L. V., Afonin, Y. A., Voronin, V. V., \& Akopyan, D. A. (2015). Financial accounting centers: Concepts and tools. Mediterranean Journal of Social Sciences, 6(4 S4), 339-344. https://doi.org/10.5901/mjss.2015.v6n4s4p339
Orlova, L. V., Sakhabieva, G. A., Vasyaycheva, V. A., \& Pronina, N. N. (2016). Impact of educational attainment on the development of female entrepreneurship in Kazakhstan. Indian Journal of Science and Technology, 9(11), 197-204. https://doi.org/10.17485/ijst/2016/v9i11/89426

Petrazhitsky, L.I. (2020). The theory of law and state taking into consideration the theory of morality. Moscow: Yurayt.

Progunova, L. V., Trokhova, E. V., \& Milonova, M. V. (2019). Internationalization patterns of BRICS Multinational Enterprises MNEs: how differ from other emerging markets? Espacios, 40, 26. https://www.revistaespacios.com/ a19v40n35/19403526.html

Radishchev, A.N. (1958). Journey from St. Petersburg to Moscow Cambridge: Harvard University Press. https://doi.org/10.2307/126257

Shaw, M.N. (2017). International Law. $8^{\text {th }}$ edition. Cambridge: Cambridge University Press. https://doi.org/10.1017/9781316979815

Spencer, H. (1960). The man versus the state. Caldwell, Idaho: The Caxton Printers, Ltd.

Uvarova, I. (2013). Legal regulation of the budgetary account and the budgetary reporting in the Russian Federation. Journal of Contemporary Economics Issues, 3. https://doi.org/10.24194/31302

Vasilleva, M. V., \& Nilova, A. S. (2011). Methodology of management of economy of regions on the basis of perfection of system of financially-budgetary control: strategic decisions and an estimation of efficiency of their realization. Management of Economic Systems, 35. https://cyberleninka.ru/article/n/ metodologiya-upravleniya-ekonomikoy-regionov-na-osnovesovershenstvovaniya-sistemy-finansovo-byudzhetnogokontrolya-strategicheskie

Vasilyeva, T.V. (1977). The written philosophy of Plato. Issues of Philosophy, 11, 152-160.

Yakhneeva, I. V., Agafonova, A. N., Fedorenko, R. V., Shvetsova, E. V., \& Filatova, D. V. (2020). On collaborations between software producer and customer: A kind of two-player strategic game. In: Ashmarina, S., Mesquita, A., \& Vochozka, M. (eds.) Digital Transformation of the Economy: Challenges, Trends and New Opportunities. Advances in Intelligent Systems and Computing, Vol. 908 (pp. 570-580). Cham: Springer. https://doi.org/10.1007/978-3-030-11367-4 56

Received on 15-01-2021

Accepted on 16-02-2021

Published on 08-03-2021

https://doi.org/10.6000/1929-4409.2021.10.74

(C) 2021 Daniyar Sarsembayev; Licensee Lifescience Global.

This is an open access article licensed under the terms of the Creative Commons Attribution Non-Commercial License (http://creativecommons.org/licenses/by-nc/3.0/) which permits unrestricted, non-commercial use, distribution and reproduction in any medium, provided the work is properly cited. 